\title{
Physical Function Subordinate Domain
}

National Cancer Institute

\section{Source}

National Cancer Institute. Physical Function Subordinate Domain. NCI Thesaurus. Code C122356.

The collection of PROMIS item scales that assess an individual's ability to carry out activities that require physical actions including more complex activities that require a combination of skills, often within a social context. 